\title{
NEW SHMAGENCY WORRIES
}

\author{
Olof Leffler
}

$\longrightarrow$

ONSTITUTIVISM IS THE VIEW that there are constitutive features of agency, actions, or propositional attitudes, actual or idealized, that explain stitutivists also usually hold that something about these constitutive features can explain the normative force of the phenomena; because we act, are agents, or have certain propositional attitudes, we are ipso facto required to follow certain norms. While constitutivists disagree about which norms we are required to follow, most have also argued that the constitutive features are inescapable, and that inescapability plays a vital role in the explanation of the normativity of these norms, as well as in replying to objections. ${ }^{2}$

But we may question how inescapable the norm-explaining features are. If we do not instantiate the constitutive features that explain norms, it seems like we can avoid the norms they are supposed to explain. In particular, we can avoid their normative force. Someone who is a shmagent-very much like an agent, but without instantiating the norm-explaining features - is very similar to an agent, but because the shmagent lacks the norm-explaining features, she is not subject to the norms. ${ }^{3}$ Hence, it seems like constitutivism is unable to explain the norms that apply to such creatures.

This problem is known as the agency-shmagency problem, or-as I call itthe shmagency objection. My aim is to show that, despite many constitutivist responses, new versions of the problem appear for most forms of constitutivism; in particular, it remains a deep problem for those who attempt to explain practical reasons of normatively forceful varieties (cf. section 1, below, for details). This

1 This characterization is rough, but it is enough for present purposes. Several possible explanatory relations seem acceptable here, e.g., grounding (assuming that grounding is, indeed, explanatory), constitution, reductive identification — or even less realist alternatives-so constitutivism allows for many interpretations.

2 Cf. Ferrero, "Constitutivism and the Shmagency Challenge" and "Inescapability Revisited"; Katsafanas, Agency and the Foundations of Ethics; Korsgaard, Self-Constitution; Velleman, How We Get Along.

3 Enoch, "Agency, Shmagency" and "Shmagency Revisited." 
means that the shmagency objection remains a significant problem for constitutivism. If a form of constitutivism that attempts to explain normatively forceful practical reasons is to be viable, it will have to avoid the new shmagency worries.

To show this, in section 1, I present the original shmagency objection. In section 2, I show how the standard reply to the objection - that the shmagent is self-defeating - seems defensible, despite several arguments to the contrary. But then, in section 3, I extend the shmagency objection by arguing that shmagents can be sophisticated enough to have practical reasons while standing outside agency. This resuscitates the problem. In section 4, I explain how sophisticated shmagency remains a problem for some other recent constitutivist attempts to avoid the shmagency objection.

In section 5, I introduce another major line of response to the shmagency objection, according to which constitutivism is defended by appeal to constitutive features we are under normative pressure to have. I call this view partial constitutivism. Partial constitutivists respond to the shmagency objection by taking our constitutions to be normatively justified, so it does not matter for their purposes if we sometimes fail to live up to them. But in section 6, I argue that partial constitutivists suffer from a second new version of the objection, because they leave the normative phenomena they are supposed to explain underdetermined. I conclude in section 7 .

\section{ENOCH'S ARGUMENT}

The paradigmatic formulation of the shmagency objection comes from Enoch. ${ }^{4}$ The basic point has often been set up using an example. Imagine that you are playing chess. There are certain rules (and maybe aims) constitutive of doing so; if you do not abide by them, you seem to be playing something else other than chess. Call this other game shmess. Why should you stick by the rules (or aims) of chess-rather than shmess - when you are deciding which game to play? A reason seems needed.

By analogy, Enoch thinks, it is unclear why we should care about what is constitutive of action or agency. We can always ask "so what?" and demand a reason for why we should be agents rather than shmagents_-something very much like agents, but not quite like agents. Or, to put the same point in a more poignant way, we can ask the shmagency question: "Why should I be an agent rather than a shmagent?"

The question is meant to illustrate that we can avoid being agents by being shmagents instead. We can, so to speak, shirk from the normative requirements

4 Enoch, "Agency, Shmagency." 
that agency is supposed to commit us to. For if we are shmagents rather than agents, we can have all the features that we would take to be constitutive of agency-or even otherwise associated with it—except those that explain the norms that hold for us.

But as constitutivists attempt to explain normative phenomena by the features that are constitutive of agency (including their inescapability), then if we can be shmagents, it seems like their explanation does not get off the ground. If shmagency is an open option for us, then constitutivists have yet to explain normative phenomena well, for they have not explained the normative force of the phenomena. ${ }^{5}$ Therefore, when I mention the shmagency question below, I take its main point to be equivalent to suggesting that agency is not comprehensive enough to explain norms. ${ }^{6}$

More formally, here is the problem:

P1. If constitutivism is true, the conditions of agency that explain (normatively forceful) practical reasons for us must be (descriptively) inescapable.

P2. We can (descriptively) escape instantiating the conditions of agency that explain (normatively forceful) practical reasons for us.

C. Constitutivism is false.

The core reasoning behind the different premises is already present in the description of the argument above. The thought behind $\mathrm{P} 1$ is that if we can escape the constitutive features of agency that explain norms, then we do not have an explanation of the phenomena these features are supposed to explain. The thought behind P2 is that we indeed can avoid instantiating the properties of agency that explain norms, for we can be shmagents, and then it is unclear why our reasons are normative for us. (Or, equivalently, we can ask the shmagency question.) The conclusion follows immediately.

Some clarifications are, however, needed before I proceed to discuss the argument. First, I have written "the conditions of agency that explain (normatively forceful) practical reasons." What does that mean? Just what normative force involves is an extremely intricate question. ${ }^{7}$ For now, a negative characterization

5 At least, this is the standard interpretation of the objection. Alternative interpretations (usually along with this one) are discussed by Katsafanas, Agency and the Foundations of Ethics; Paakkunainen, "Doing Away with the 'Shmagency' Objection to Constitutivism”; Rosati, "Agents and Shmagents"; and Smith, "The Magic of Constitutivism."

6 This core point can be extended further with other plausible assumptions-e.g., if we need reasons to be agents, then plausibly those reasons may need to be external to agency, so constitutivism cannot explain all reasons. But the expansion is secondary to the main objection. 
will do: a practical reason, pro tanto or overall, for an agent $A$ to $\phi$ is normatively forceful iff the reason cannot legitimately be ignored because $A$ arbitrarily desires or wants something else than to $\phi{ }^{8}$ This means that the argument applies to all constitutivist views that attempt to give positive explanations of such practical reasons-not least of moral reasons. ${ }^{9}$ These are the forms of constitutivism most participants in the debate have focused on, and the ones I will have in mind when I write "constitutivism" below.

I suspect that the shmagency objection mainly is a challenge for constitutivism about practical reasons of this kind. It has often been aimed at all forms of constitutivism, but it is not clear whether all forms of constitutivism are affected by it. For example, constitutivism about epistemic reasons, e.g., where reasons for belief are explained as truth-conducive considerations because truth is the aim of belief, need not be at fault. It is not obviously implausible to think that we do not have reasons for belief unless we have beliefs from the start.

More examples of forms of constitutivism where shmagency seems unimportant can probably be provided. But how such forms of constitutivism may be affected by the shmagency objection is beyond the scope of this paper. If the reader thinks that her favorite form of constitutivism suffers from the shmagency objection even though it is not one about normatively forceful practical reasons, she should feel free to reinterpret the rest of my discussion in her favored way. For now, I shall focus on constitutivism about normatively forceful practical reasons.

Second, the notion of inescapability in the argument is fairly complex. The standard interpretation of inescapability is that it is some descriptive form of necessity, not normative necessity. In particular, I am explicit that the form of inescapability involved here is descriptive, because this assumption will be tweaked below. In sections 5 and on, I will discuss normative inescapability, according to

8 This characterization is not intended to be comprehensive; much more can be said about normative force (or "prescriptivity," "directivity," "commendation," or whichever term one prefers for this elusive phenomenon). The core point here is that, while it is highly unclear how normative force (or "prescriptivity," "directivity," "commendation," etc.) should be characterized, a shared commitment of all plausible views about it is that one cannot ignore something that has such force just because one desires to do something else, or does not want to, if that desire or want is not forceful in itself (i.e., is "arbitrary"). If the desire or want lacks normative standing, then it has no normative force itself. Notably, this is why normative force cannot be treated as just outweighing opposing desires-outweighing implies that desires or wants, too, have force. But they need not.

9 E.g., Katsafanas, Agency and the Foundations of Ethics; Korsgaard, The Sources of Normativity and Self-Constitution; Smith, "Agents and Patients" and "The Magic of Constitutivism"; and Velleman, How We Get Along. 
which it is normatively desirable to be the kind of agents that can explain norms. But more about that later.

Instead, for now, assume that the kind of inescapability that is involved in the shmagency argument is dialectical inescapability. ${ }^{10}$ Dialectical inescapability is a descriptive form of inescapability, for it is something that an agent has, rather than one that she ought to have. Ferrero characterizes it as "the inescapability of rational agency in the sense of the closure of this agency under the exercise of its distinctive operation." ${ }^{11}$ What is inescapable is the agency that an agent already has, and agency is inescapable because it is self-defeating to attempt to escape agency, as acting so as to escape it involves exercising one's agency. This form of inescapability might possibly work to ward off the shmagency objection-I discuss the argument for thinking that it may do so in depth in section 2, below.

Third and finally, all forms of constitutivism I discuss set out some (inescapable) feature(s) as a condition of agency, actions, or propositional attitudes. It is this feature (or these features) that explains normative phenomena. But, for simplicity, I will refer to all those possible norm-explaining features as "agency."

\section{INESCAPABILITY AND SELF-DEFEAT}

The most common reply to the shmagency objection is to deny the argument for P2. We cannot, it is claimed, properly ask the shmagency question. This standard response comes from a dilemma based on a distinction between an internal and an external way to ask it. The question is internal if it is asked by someone who already is an agent, but external if it is asked by someone who is not. The internal question is largely unproblematic, for it is a normative question whether an agent ought to be an agent. Maybe one ought not to be an agent, but at least constitutivists can try to give reasons for or vindications of why one should be an agent as soon as one has come this far. And as long as one remains an agent, constitutivists can provide whatever positive explanation of practical reasons they want.

However, according to the standard reply, the external question does not arise. The most important reason for thinking that it does not is that anyone asking the question already is an agent, so it is self-defeating to ask it. Asking the

However, as Ferrero ("Inescapability Revisited") points out, this kind of inescapability need not be the kind that many constitutivists think explains normativity, such as the one Korsgaard (Self-Constitution, 1-2) suggests when she says that agency is our "plight." But whatever positively explains normativity is orthogonal to the present discussion.

11 Ferrero, "Inescapability Revisited," 128. 
external shmagency question is still an action, and hence subject to the norms explained by agency. Hence, agency is (dialectically) inescapable.

One version of this response, paradigmatically formulated by Ferrero, has generated most of the ensuing discussion. ${ }^{12}$ I will start off by defending this argument, and hence constitutivism, against some recent responses. However, in the next section, I shall point out a deeper problem posed by shmagency, hence criticizing $\mathrm{P} 2$ anyway.

According to Ferrero's response, then, agency is dialectically inescapable in virtue of two properties. ${ }^{13}$ First, agency is the enterprise of the largest jurisdiction, so all actions fit within its scope. Playing chess and playing shmess are both actions, while a shmagent does not act in the same way as an agent. Second, agency is closed under reflection, meaning that reflecting on how to get out of agency, let alone actively trying to do so, still counts as acting. It is, admittedly, logically possible to opt out of agency, e.g., by committing suicide. But once one is an agent, one cannot deliberately avoid being an agent without exercising one's agency.

The key argument, then, is that because agency is the enterprise of the largest jurisdiction, and one cannot opt out of it in the same way that one could decide to play shmess rather than chess, there is no alternative to it once one is in the game. One cannot deliberately leave for something else without exercising it. Hence, it is self-defeating to ask the shmagency question for an agent. Agency is dialectically inescapable.

I will proceed by presenting three points that can be construed as replies to the charge that shmagency is self-defeating. First, Enoch provides two such considerations. ${ }^{14}$ Responding to an interpretation of Velleman, according to which Velleman considers it constitutive of agency to care about one's constitutive aim - so caring about it is inescapable, and this explains why we are subject to norms-Enoch writes:

What we are up against here is an especially problematic instance of [a naturalistic fallacy].... I want to concede that agency is indeed naturally inescapable for us. But I also want to note ... that such inescapability does not matter in our context.... For the move from "You inescapably $\phi$ " to

12 Ferrero, "Constitutivism and the Shmagency Challenge." Cf. Ferrero, "Inescapability Revisited”; Katsafanas, Agency and the Foundations of Ethics; Korsgaard, Self-Constitution; Rosati, "Agents and Shmagents"; and Velleman, How We Get Along.

13 Ferrero, "Constitutivism and the Shmagency Challenge," 308-9.

14 Enoch also presents several other, less related, points ("Shmagency Revisited"). For example, he discusses the plausibility of the constitutive aims that constitutivists defend. But that has little to do with shmagency. 
"You should $\phi$ " is no better-not even the tiniest little bit—-than the move from "You actually $\phi$ " to "You should $\phi . " 15$

The objection here is that constitutivism suffers from a version of the naturalistic fallacy. But the objection shifts the topic. It does not seem to have much to do with dialectical inescapability. As Ferrero points out, dialectical inescapability need not by itself be used to explain any norms. Because it is not the property to which constitutivists appeal to explain why a norm is normative, it is not subject to a naturalistic fallacy. ${ }^{16}$ Dialectical inescapability only shows why one cannot avoid agency once one is an agent.

The positive explanation tends to be provided by some other inescapability-related property, such as Korsgaard's plight inescapability. ${ }^{17}$ On my interpretation, according to plight inescapability, we cannot avoid being subject to norms because we keep being faced with new choice situations where we must act, so we must both continuously face the demands of agency and cannot actively leave it (as according to dialectical inescapability). ${ }^{18}$ But it is the former conjunct that explains how we keep being subject to the norms of agency. The naturalistic fallacy charge is aimed at the positive explanation that plight inescapability might provide, as is the talk about a move from "You actually $\phi$ " to "You should $\phi . "$

Having said that, it could be argued that this response of Enoch's still is a problem for constitutivists, because it shows that they have to say more to explain normativity. But that is a point that constitutivists happily may concede, and then go on to try to provide such an explanation, for example by appealing to plight inescapability - though whether they succeed is a different question. Regardless, naturalistic fallacies seem beside the point at the present stage of the shmagency dialectic; constitutivists are allowed to say that one cannot avoid agency and then supplement their explanation of normative phenomena with any explanans they want.

Enoch's second response is that constitutivists turn the skeptic into an actual character that they try to convince. They try to show that the potential shmagent cannot get out of its predicament of being an agent. That means that they do not face the conceptual problem that the shmagency objection stems from. As he 
puts it, the skeptic "is not ... an actual character, with a position to defend, [but] the embodiment of a problem we face, because of our commitments." 19

The shmagency objection should instead be understood as a problem for our concept of agency. The challenge is that constitutivism does not show why we would have to be agents even if the shmagent is self-defeating because she asks the shmagency question. The self-defeat response would, in a way, be an ad hominem charge of hypocrisy against the shmagent. But such hypocrisy is irrelevant-hypocrisy does not imply that our concept of agency is such that there is no question to ask about why one ought to be an agent. It only shows that the hypocrite is in a place where asking the shmagency question becomes hypocritical because she already is committed to being an agent. But whether she should be an agent is what is at issue.

To this point, Ferrero has replied by conceding that there is a sense in which he treats the shmagent as an actual character. ${ }^{20}$ But this does not matter. Here Ferrero relies, again, on the distinction between internal and external questions. The shmagent occupies a position external to agency and asks whether it should become an agent, but that position can be shown to be self-defeating (by the argument above). This leaves the internal question-why an agent should care about being an agent, rather than a shmagent-open. But the reply to the internal question is distinct from the dialectical inescapability of agency, which can defuse the external question. Again, constitutivists can respond to the internal question however they want. It is enough for them to avoid the external one.

A third reply to the inescapability worry comes from Tiffany. ${ }^{21}$ Tiffany accepts Ferrero's point that the external question is self-defeating. However, he also holds that the kind of agency one cannot opt out of is too minimal to explain strong normative standards, such as those that normatively forceful reasons can provide us with. Hence, Tiffany thinks, some form of constitutivism may be true about some extremely weak norms, but not stronger norms.

The underlying reason for this is that he believes that constitutivists equivocate on the nature (or, possibly, concept) of agency. According to Tiffany, just because we cannot opt out of some weak form of agency, it does not follow that agents cannot opt out of substantive constitutivist-style agency that might explain norms. Maybe a minimal agent can be an agent in the sense, for example, that she is able to act for reasons. But constitutivists start off from substantive theories about agency that involve more than minimal agency. For example, Kantian constitutivists like Korsgaard think that agency requires a commitment

19 Enoch, "Shmagency Revisited," 219.

20 Ferrero, "Inescapability Revisited," 131.

21 Tiffany, "Why Be an Agent?" 
to the categorical imperative. ${ }^{22}$ Yet the minimal agent need not be committed to anything that strong.

However, Tiffany's equivocation response goes by too quickly. It seems to beg the question. Constitutivists often attempt to explain reasons in terms of some features of (presumably intentional) agency as such. ${ }^{23}$ This means that there is no weaker version of agency out there-or, at the very least, constitutivists can hold that there is only one type of relevant agency, whereas other forms (e.g., animal agency) are extremely different and hence need not have the same normative commitments. ${ }^{24}$ So constitutivist theories of agency differ from minimalist theories not by taking there to be different standards of agency for different (relevant) agents, but by claiming that agency involves much more than some weak standard like the ability to act for reasons from the start. If constitutivists are right, it follows that every agent (or every normatively relevant agent) is committed to everything that agency involves.

But might one not think that there are several forms of normatively relevant agency from the start, like Tiffany and others appear to do ${ }^{25}$ Why would agency be unified so as to generate the same normative reasons for all? The option is, admittedly, theoretically open. But absent an argument in its favor, it still seems question-begging. Constitutivists can answer: Why should we believe that there is more than one kind of (normatively relevant) agency? More would have to be said to give constitutivists reason to go with a disunified account.

\section{NORMATIVITY FOR SHMAGENTS}

I have just presented three lines of defense of the inescapability reply to the shmagency objection. There still seems to be a sense in which at least the standard kind of agency remains dialectically inescapable, and the skeptic therefore self-defeating. However, I shall now argue that P2 remains defensible. Even though the original shmagency question can be avoided, the objection can be extended in a way that makes the original problem remain.

How so? The final response to the shmagency objection that I discussed and criticized was Tiffany's equivocation response. Even though it begs the question, there is still something to his point that different ways of being might generate different normative results. We may well accept the constitutivist response to the shmagency question and make a deeper point that threatens P2.

22 Korsgaard, The Sources of Normativity and Self-Constitution.

23 Cf. Katsafanas, Agency and the Foundations of Ethics, 37-46.

24 Cf. Korsgaard, Self-Constitution, chs. 3-7, and Fellow Creatures.

25 E.g., Lavin, "Forms of Rational Agency." 
This is because insofar as we want to explain strong norms, such as normatively forceful practical reasons, we need to know more than who is an agent. Regardless of what agency involves, as long as the constitutive feature(s) used to explain reasons is relatively complex-and all constitutivist views under discussion are in agreement here-constitutivists will have trouble giving a good enough explanation of the normative reasons that hold for many creatures that appear to have them. Some of them can stand outside agency and ask the shmagency question. So constitutivism does not seem to provide a good explanation of reasons because it cannot explain the reasons of some creatures who have them. Therefore, it lacks explanatory power even when construed as a theory about subsets of the reasons there are.

In particular, constitutivists cannot explain reasons for what I will call sophisticated shmagents. Sophisticated shmagents appear to have reasons and stand outside agency, so such shmagents can ask the external shmagency question. This vindicates P2. (We can call the fact that they appear to have reasons, or at least something reasons-like, the problem of normativity for shmagents.)

But who are sophisticated shmagents? I stipulate that they are shmagents who are intelligent, knowledgeable, and perform what looks a lot like actions for what looks a lot like reasons - and, I shall argue, what well may be reasons. ${ }^{26}$ They are also capable of (what looks like) deliberation, reflecting on what they do, and are able to prefer different actions to different extents. Accordingly, they seem like prima facie good candidates for participating in ordinary normative practices, such as that of giving reasons for their actions when asked why they are doing what they do.

But sophisticated shmagents cannot act and are not agents according to constitutivists. This is because they lack at least one-possibly all-of the constitutive features of agency that constitutivists also use to explain reasons. Since constitutive features are necessary features, without them the sophisticated shmagents fail to qualify as agents.

26 If one wants to use the word "reasons" conservatively, one can call what sophisticated shmagents have "shmeasons"- but they still seem to have exactly the same kind of role and force as reasons do for agents. So reasons and shmeasons are still equivalent. Hence, if we think more deeply about who the creatures that lack the reasons-explaining features are, it does not seem like they do not have reasons-instead, they seem to function surprisingly much like agents (who have reasons), so we have good reason to think that they do have reasons.

In fact, we have no pre-theoretical reason to think that what they have should not be explained in the same way as the reasons of agents. And it would be fallacious to think that, just because constitutivists can explain reasons for agents by appeal to the constitutive features of agency, there are not some reasons for shmagents that they cannot explain. Just because constitutivists can explain one part of the normative sphere (for agents) does not mean that there is nothing more to it. 
We can concede to constitutivists that agency should be understood in their preferred ways; in fact, as I argued in response to Tiffany, we should do so, or else we beg the question against most constitutivists. But with that concession made, there remains a conceptual and normative space where sophisticated shmagents, characterized as above, can operate. And if they can do so, a problem re-emerges for constitutivism. Sophisticated shmagents can ask the external question about whether they should be agents, i.e., they can reason practically about whether or not they should be agents, since they have what appears to be reasons. However, being shmagents, they still stand outside agency-in other words, they are external to agency. So it seems like they can ask the external shmagency question. ${ }^{27}$

Moreover, they can do so independently of the dialectical inescapability of agency. To rehearse the last section: my responses to objections to Ferrero's argument were (i) that the naturalistic fallacy point does not matter because the fallacy has little to do with dialectical inescapability, (ii) that it does not seem to matter that constitutivists reify the shmagent because they can still defuse the external question, and (iii) that because constitutivists think agency involves a lot from the start, it begs the question to hold that only minimal forms of agency are inescapable.

Yet none of these responses indicate that there cannot be sophisticated shmagents. The responses can be avoided as follows: (i) the explanation of reasons in terms of agency is neither here nor there if we can escape agency, which sophisticated shmagents can; (ii) because sophisticated shmagents stand outside agency from the start, they can ask the external shmagency question; and (iii) sophisticated shmagents are shmagents, ex hypothesi, so they have little to do with what constitutivists take agency to involve.

I shall illustrate how such shmagents appear to have reasons while standing outside agency, vindicating P2, by discussing Korsgaard's theory of agency. Assume that she is right about the nature of agency. She thinks that it entails that agency must be regulated by the categorical imperative (CI), because we need to unify ourselves to act, and that, she thinks, fundamentally involves being regulated by cr. The core idea is that acting involves acting on maxims, these need to

I suspect that sophisticated shmagency is a problem here because philosophers have focused too much on shmagency as an offshoot of agency. Shmagency is usually taken to be agency minus the normativity-explaining feature that agency purportedly has (and possibly minus something else, but only little else). Hence, one might become a shmagent if one loses some agency-constituting feature. But shmagents can be extremely cognitively and maybe even normatively sophisticated, in the manners just described, while standing outside constitutivist agency. 
be universalized, and universalization must proceed in line with CI. If not, we are mere heaps, not agents. ${ }^{28}$

But assume simultaneously that we have some sophisticated shmagents. Call them the Martians. A traditional Humean belief-desire theory is true about how the Martians behave or otherwise interact with their environment (rather than act, since only agents can act), intentionally or not, and that their ordinary behavior or interaction usually stems from belief-desire combinations of mental states. These are not in any way regulated by CI. There is no need to appeal to maxims, universalization, or being in line with CI to explain their behavior; such features, which Korsgaard takes to explain why we are bound by CI, are in no way part of their psychologies. Hence, they lack the norm-explaining features that she thinks are constitutive of agency.

Or consider some other sophisticated shmagents - the Saturnians - whose behavior or interaction stems from besires, i.e., mental states that both represent the world and push them to behave in certain ways. Again, they lack the features that might seem to bind us to CI. Examples of creatures with different kinds of psychological setups can be multiplied pretty much indefinitely here; they all lack the conditions that are constitutive of agency and constitutivists take to explain reasons. ${ }^{29}$ I focus on these two, however, as they exemplify psychologies that philosophers often have thought explain action.

The Martians and Saturnians fail to qualify as agents on the theories of agency that constitutivists like Korsgaard, who want to explain normatively forceful practical reasons, hold. There is, ex hypothesi, no way that their "actions" have the typical constitutivist aims. Again, maxims, universalization, or being in line with CI have nothing to do with the explanation of their behavior. It follows that they do not aim at following norms such as $\mathrm{CI}$ (in any relevant way, at least), and hence do not have reasons on Korsgaard's view.

Yet they still appear to have reasons. They are sophisticated and are therefore, pre-theoretically, on par with at least humans insofar as reason-possession goes. I have already assumed that sophisticated shmagents have all kinds of properties that indicate that they have reasons: they are intelligent; are knowledgeable; perform what looks a lot like actions for what looks a lot like reasons; are capable of (what seems to be) deliberation and reflecting on what they do; and are able to

\section{Korsgaard, Self-Constitution, 72-80.}

An anonymous reviewer has suggested that they may still be regulated by $\mathrm{CI}$ even though that is not their self-understanding. I do not deny that; I have not discussed self-understanding. The point is rather that the features that might commit one to $\mathrm{CI}$ are not involved in their psychologies at all, and a lot of argument would be needed to show that belief-desire pairs require it. 
prefer different behaviors. And they seem to be prima facie good candidates for participating in normal normative practices.

Moreover, here is a number of things we take to be true about reasons. First, (i) they are facts counting in favor of something (for someone), so they would have to be reasons for someone. Furthermore, (ii) they appear to be normatively forceful (at least for those who have them), (iii) they depend (e.g., supervene on, or are grounded in) natural facts, (iv) they come in varying strengths (or weights), (v) they can contribute to generating all-things-considered reasons, and (vi) they have impact on deliberation.

All the properties that reasons are supposed to have seem possible to instantiate without having a constitutivist-style constitution. For example: Let a Martian deliberate (or deliberate*, if you want to reserve the word "deliberation" for a kind of action that constitutivist-style agents perform). Let it also deliberate using facts; its desires might be backgrounded. ${ }^{30}$ From its perspective when deliberating, it represents facts - which may or may not seem desired-when deliberating.

Using representations of these facts, the Martian judges which ones count in favor of what to do (i). It is these facts that appear, to the Martian, to be relevant to determine what it is to do by favoring different outcomes (ii). ${ }^{31}$ Moreover, the facts that it takes into consideration seem to stem from natural properties, e.g., if something is pleasant or painful for the Martian (iii).

Now, the Martian thinks these facts can matter to different degrees (iv), but weighs them up, and tries to reach a conclusion about what to do based on what it most strongly favors. Because it is knowledgeable and intelligent, it can do this to quite a significant extent. What appears to be reasons therefore comes in different strengths depending on how it weighs things up (v), and they have been part of generating what looks like an all-things-considered reason. The Martian, then, seems to be deliberating with reasons (vi). And all this could be said about the Saturnians as well.

Again, it certainly seems like the Martians or Saturnians have reasons, or at least something that plays the role of reasons. Because these creatures stand outside constitutivist-style agency, there is a perspective from which it makes sense to ask the external question about whether they should be agents or shmagents. 
So we can preserve $\mathrm{P} 2$ in the original argument. So the shmagency objection stands.

Unsurprisingly, there are some worries about this defense of the shmagency objection. First, it might be claimed that it does not matter that there are shmagents who occupy a place outside agency from which they may ask the shmagency question. For one could hold that what matters is whether agency is inescapable for creatures like us, who already are agents. If it is, for example, psychologically impossible for us to have belief-desire psychologies or besires because we are the kinds of creatures who have Korsgaard-style constitutions, and these cannot be altered, becoming shmagents is not a live possibility for us. ${ }^{32}$

It seems possible that we might not be able to become shmagents. I have defended the inescapability of agency for agents in section 2, and then tried to argue that the real shmagency problem comes from creatures like the Martians or Saturnians who never may have been agents in the first place. The shmagents may or may not ever have been agents.

But because they still seem to have reasons, or something very much like reasons, that normative phenomenon should be explained in the same way that we explain reasons for ordinary agents. ${ }^{33}$ We should want a general explanation of (what looks like) normatively forceful practical reasons. But then, constitutivism seems ill suited to explain a phenomenon like normatively forceful practical reasons if its explanation is limited to agents' reasons and not the reasons of sophisticated shmagents - it only seems able to explain a subset of our observations of the reasons there are. So constitutivism does not seem very explanatorily powerful because it cannot handle all the reasons there are. Hence, it is likely false, even about reasons for ordinary human agents.

A second possible response is to say that the kind of reasons that shmagents have are somehow different from, and probably of less normative interest than, those that constitutivist-style agents have. Or, similarly, one might think that what I have called shmagents are agents of another kind than standard constitutivist agents, and then argue that one should explain their reasons in different ways.

Versions of this point are already made in the constitutivist literature. Most obviously, Lavin thinks there can be different kinds of agents who have different kinds of norms applying to them in virtue of having different kinds of constitutions. ${ }^{34}$ Similarly, Korsgaard thinks that while humans indeed act in accordance with universalized principles - and our fundamental principle is $\mathrm{CI}$-for ani-

32 Thanks to an anonymous reviewer for raising this point.

33 Cf. note 26 , above.

34 Lavin, "Forms of Rational Agency." 
mals, instincts work as the right kind of principles. ${ }^{35}$ By distinguishing between different kinds of principles, we can make sense of different kinds of agency, and, possibly, different kinds of reasons that stem from different sources.

But appealing to different kinds of reasons seems disingenuous insofar as we are talking about agents and shmagents instead of when we contrast, for example, human beings and animals. We can easily make further assumptions about the Martians and Saturnians that explain why it seems like they have reasons in the ordinary sense of the word. When I characterized them, I stipulated that they have all kinds of properties that make them seem to have reasons, and I have also showed how what looks like reasons might feature in their phenomenology. Examples of properties needed to have reasons in the ordinary sense of the word can be multiplied, since the Martians and Saturnians are creatures that we construct. They can always be made sophisticated enough to seem to have reasons in the ordinary sense.

\section{OTHER REASONS TO DISMISS THE EXTERNAL QUESTION}

I have now motivated the shmagency worry again. Sophisticated shmagents seem to have reasons and stand outside agency, so they can ask the external shmagency question. However, some other motivations than the self-defeat argument from section 2 have also been proposed for explaining why the external question fails to make sense. If either of these is right, P2 would be defended. I shall first discuss a semantic response, and then a metaphysical one. ${ }^{36}$ I shall argue that these responses, too, fail due to considerations that have appeared in the discussion in the previous section. The responses attempt to show that it is impossible to ask the external shmagency question, but sophisticated shmagents can do so.

First, there is a second strand of argument in Velleman's response to the

Korsgaard, Self-Constitution, 3-7, and Fellow Creatures.

Some responses can be treated more quickly. O'Hagan ("Shmagents, Realism and Constitutivism about Rational Norms") seems to endorse both types of response, but she is not able to face the challenge for Tiffany from section 3. She tries to defend constitutivism by arguing that shmagents must deny a minimal norm of reasons-responsiveness, but it does not follow from that norm that constitutivists must accept enough material to be able to explain normatively forceful practical reasons. Furthermore, Rosati ("Agents and Shmagents") argues that the difference between agents and shmagents is greater than what Enoch has assumed, but once we see that, we realize how much more valuable agency is to us. So agency matters because it is valuable. But, obviously, that requires her to have a take on values that is independent of what we can squeeze out of agency if it is to answer the skeptic. I discuss such responses in sections 5 and 6, below. 
shmagency objection. ${ }^{37}$ The idea is that the external question-asking "Should I be an agent or a shmagent?" from the perspective of a non-agent-does not make sense because it is semantically defective. It looks analogous to "Is a tree taller?" without specifying what the tree might be taller than. If so, it is conceptually impossible to ask the shmagency question, and so the possibility that we might end up outside agency is no challenge to constitutivism.

However, as Enoch points out in his response to the argument, shmagency-style questions do not seem defective. ${ }^{38}$ Asking whether one should be an agent or something like it, or if one has reason to be an agent, seems perfectly intelligible. So, prima facie, shmagency-style questions do not seem defective.

Yet seemings can be erroneous, so maybe we need a deeper reason to think that they are correct in this case. One such reason stems from the point that the intelligibility of the external question does not stand or fall with the possibility of shmagency for creatures who already are agents. If the external question is unintelligible, it would make no sense for sophisticated shmagents, standing outside agency but having reasons, to ask the shmagency question. But whether sophisticated shmagents should become agents or not clearly matters for themassuming some constitutivist view is right about the normative commitments and implications of agency, they would be subject to different norms if they were to become agents, which no doubt matters from their perspectives. This would not have made sense if the shmagency question had been conceptually confused. Hence, the external question does not seem semantically defective.

Another attempt to motivate the failure of the external interpretation of the shmagency question comes from Silverstein. ${ }^{39} \mathrm{He}$ thinks that it makes sense to ask it, but that it is ambiguous between the internal and external versions of the question. The internal question makes sense, but the external one does not. A shmagent — who is not an agent—would be asking for reasons for actions though she has none, but anyone asking the question is already an agent. So the external reading of the question begs the question against the constitutivist picture of normativity, according to which it is agency that explains why something is a reason:

It is tempting to interpret the shmagent's question as one about reasons for action: Do I have any reason to become an agent rather than a shmagent? But that cannot be right, for a shmagent is not in a position to perwhether Velleman himself actually endorses it. 
form actions. Only agents can act, and so only agents can be in the market for reasons for action. ${ }^{40}$

However, this answer is unsatisfactory due to the problem of normativity for shmagents. Sophisticated shmagents are still in the market for reasons (or something reasons-like) for action (or for something action-like), and the external question certainly seems intelligible for an intelligent being who does not count as an agent according to the strong constitutivist theories of agency. So again, the external shmagency question remains a live possibility.

\section{PARTIAL CONSTITUTIVISM}

I have now argued that there are shmagents that plausibly have normative reasons, and hence defended P2. Can constitutivists respond to the shmagency objection in a better way? A number of authors have recently defended views according to which we-most directly_-should be agents normatively, rather than descriptively. For example, Michael Bratman has argued that norms constitutive of planning agency are justified in virtue of their value for our self-governance. ${ }^{41}$ And though she does not commit herself to constitutivism, Caroline Arruda has argued that the reason we ought to be full-fledged agents is not, as constitutivists have argued, that full-fledged agency is inescapable, but because it allows us to pursue other valuable projects that require exercising full-fledged agency. ${ }^{42}$ It seems easy enough to turn her point into an argument for a form of constitutivism saying that we ought to endorse norms constitutive of full-fledged agency because of their general value for us.

Most importantly, however, Michael Smith has formulated a new version of constitutivism that diverges from previous accounts in interesting ways. ${ }^{43}$ Because this view is the most developed theory in print according to which a deeper norm allows us to explain reasons in a constitutivist way, I shall use it to exemplify the second response strategy to the shmagency objection. ${ }^{44}$

Silverstein, “The Shmagency Question," 1136.

Bratman, "The Rational Dynamics of Planning Agency."

Arruda, "Why Care about Being an Agent?"

Smith, e.g., "Agents and Patients," "The Magic of Constitutivism," and "Constitutivism."

Beyond the three views just mentioned, the first hint of such a view is arguably in Bagnoli (Constructivism in Ethics, 11), though she does not develop the point in detail. Moreover, Paakkunainen ("Doing Away with the 'Shmagency' Objection to Constitutivism") has recently presented an interesting view in the vicinity of those I have in mind. Her response to the shmagency objection says that reasons can be grounded in features of agency that we need not instantiate. It does not seem committed to taking those features to be normatively 
We can call the type of views mentioned above versions of partial constitutivism. The core idea here is that the constitutive conditions of agency that are supposed to explain normative phenomena such as reasons are normatively defended themselves. So the kind of agency that explains some normative phenomena is normatively justified from the start, but can still do explanatory work regarding other normative phenomena. Quite generally, we can characterize partial constitutivism like this:

Partial Constitutivism: For all forms of constitutivism, a form of constitutivism is a form of partial constitutivism iff the constitutive features of agency that explain normative phenomena are normatively justifiable (or desirable, required, etc.) to instantiate for someone, rather than only descriptively necessary for one to instantiate to be a member of some kind.

I call partial constitutivism "partial" because, on this view, it is not the case that all norms are explained by constitutive features that an agent only descriptively instantiates. Instead, at least one norm is a deeper feature of the explanation, suggesting what type of agent one is justified in being. That type of agency becomes normatively, not descriptively, inescapable. This norm (or these norms) may or may not be further reducible to descriptive constitutivist or naturalistic terms - but whether it (or they) can is an open question that one need not take a stand on. ${ }^{45}$

Partial constitutivism stands in contrast with standard forms of constitutivism in at least two ways. First, it is in one sense normative rather than descriptive. The constitutive features of agency by which some interesting normative phenomenon is explained are normatively justifiable (or desirable, required, etc.), and that is why one should instantiate them. They may or may not also be descriptively necessary for agency-one may have to live up to the standards of agency in some minimal sense to count as an agent at all. But then, those normative standards in turn impose stronger norms on an agent-e.g., to be a fully functional agent. Or, alternatively, it may be that there is some sort of external normative justification for being an agent of the relevant kind.

By contrast, according to standard formulations of constitutivism, the con-

justifiable for us, so it differs slightly from the partial constitutivist solution to the problem that I will present-this solution is formulated in terms of a kind of normative inescapability. Nevertheless, her positive suggestion for how one might formulate a form of constitutivism that avoids the shmagency objection still relies on a kind of attributivism about goodness, making it very similar to Smith's view that I will present in detail—and, I think, susceptible to the problem I will raise for his type of view. I hope to discuss her suggestions in more detail elsewhere.

However, at least Smith ("Constitutivism") believes that it is so reducible. 
stitutive norms are explained by non-idealized properties that constitute something as a member of their kind simpliciter. One must instantiate them to at least some extent to count as a member of some kind, but the constitutive conditions themselves need not put direct normative pressure on agents. Whether one should be an agent of some kind is a separate question from whether one is one.

Second, partial constitutivism is less comprehensive than many standard forms of constitutivism. ${ }^{46}$ It does not attempt to explain all practical norms or all moral norms, but rather uses some normative feature to explain agency, which in turn explains some other normative phenomenon, such as reasons. This might seem to make it less ambitious, and therefore less attractive, than the standard forms of constitutivism. But the view still does substantive work to explain some normative phenomena (e.g., reasons) in terms of others (e.g., perfectly good agency), and so remains informative.

As mentioned, partial constitutivism can be exemplified using Smith's view. What Smith has done is to start to label his older ideal advisor theory of reasons a form of constitutivism. ${ }^{47}$ On his present view, our reasons for action are explained by having their sources in the desires of our ideal counterparts, where our ideal counterparts are perfectly good qua agents. Agency is taken to be a goodness-fixing kind, i.e., a kind that itself sets out the features that something has to have to be a good member of it. Moreover, a perfect exemplar of an agent, Smith thinks, is fully practically and theoretically rational, and rationality is spelled out in terms of coherence.

To explain reasons, then, Smith appeals to a prior conception of goodness for an agent. The goodness here is functional; a perfectly coherent agent is a perfectly functioning agent. Furthermore, Smith thinks that functional goodness should be understood in terms of features that are constitutive of agency. ${ }^{48}$ Again, as mentioned, it does not matter for theoretical purposes whether the functional goodness here is constitutivist, as long as one can get to the explanation of reasons in terms of the responses of perfectly functioning agents. That is still what Smith gives us: one can explain reasons in terms of the desires of perfectly functioning, or perfectly rationally coherent, agents, where that type of functional perfection is understood independently of our reasons.

So Smith is a partial constitutivist. He takes fully functioning agency to be able to explain normative reasons, and it is good for us to be such agents be-

46 E.g., Korsgaard, The Sources of Normativity.

47 E.g., Smith, The Moral Problem, ch. 5; cf. Smith, "Constitutivism."

48 Smith thinks that this is a form of constitutivist explanation too, taking any explanation of something normative in terms of the constitutive features of that thing to be constitutivist ("Constitutivism"). 
cause agency is a goodness-fixing kind. Doing so, he-like other partial constitutivists - is able to deny premise P1 rather than P2 in the original shmagency argument. For according to partial constitutivists, it is irrelevant whether or not actual agents are ideal. Their reasons can be explained regardless, for the kind of agency that explains norms is not descriptively inescapable, but normatively inescapable-on Smith's view, this is because it is good to be a perfectly functioning agent. Importantly, it does not even matter whether the reasons that one attempts to explain are the reasons of a member of some kind of entity that does not instantiate agency. Even the reasons of Martians or Saturnians can quite possibly be explained by the responses of idealized agents.

Hence, on a partial constitutivist view, it is possible to explain normatively forceful practical reasons without requiring the agency in terms of which they are explained to be descriptively instantiated - it is idealized agency that explains reasons, not actual agency. On this view, questions about whether we should be agents or shmagents are first-order normative questions about which reasons we have, but the reasons themselves have a deeper explanation. ${ }^{49}$ So partial constitutivists seem able to explain at least some normative phenomena without invoking the argument against P2 discussed in the previous sections.

\section{SHMAGENCY AS UNDERDETERMINATION}

Unfortunately, partial constitutivism lends itself to another version of the shmagency objection. In sections 3 and 4 , I defended P2 in the shmagency argument. The external shmagency question still stands if constitutivists cannot explain shmagents' reasons. But I just argued that partial constitutivists can deny P1, for we need not be ideal agents descriptively, only normatively, and ideal agency remains the same regardless of who we are, descriptively.

However, a normatively analogous version of $\mathrm{P} 2$ remains. This is a problem of underdetermination: the reasons that are explained by some form of justifiable (or desirable, required, etc.) agency do not seem normatively preferable to other, slightly different, potential reasons that can be explained by treating the same justified (or desirable, required, etc.) agency somewhat differently. There seems to be little reason to prefer one explanation of reasons in virtue of normatively justified agency to other such explanations, for the reasons that are to be explained in such terms can be given different interpretations depending on the extent or manner in which we should treat such agency. And there are many possible ways of baking the same normatively justified form of agency into our 
reasons, immediately yielding many possible candidate theories that might explain our reasons.

This problem exists because it is unclear how we should treat the normatively sanctioned form of agency that explains reasons. For, very plausibly, there are different ways to respond to the same normative feature that it might have, which gives rise to different possible sets of reasons that are explained by forms of agency with it. For example, if the normative feature is some form of goodness or value, we can ask: Ought the goodness or value of agency be maximized, satisficed, used to explain only some subset of our reasons, respected, honored, promoted, or something else? Until we have an answer to this question, we can always ask: "Why should I care about what an ideal advisor tells me rather than what a shmideal advisor tells me?" where the difference between an ideal and a shmideal agent is that we treat their goodness or value differently.

We can also exemplify this problem using Smith's view. Why should we be concerned with any of the alleged reasons that the desires of our ideal counterparts supposedly grant us in virtue of functioning perfectly? There is, on his view, some sense in which it would be good to be fully functioning agents, and still good—but possibly less good—-to be slightly less perfect as an agent. But no reason is provided for thinking that we ought to care more about reasons that have their sources in the desires of a perfectly functioning agent than a slightly less perfectly functioning agent. Being the latter type of agent may not be as attributively good for us as the former, but their responses may still be what gives us reasons. So until we know what to do with the value of agency, it seems like it is not just ideal agents, but also less than ideal agents, that have desires that seem decent candidates for giving us reasons. This gives rise to the shmagency question: Why should we care about what an ideal advisor rather than a shmideal advisor desires?

This type of problematic underdetermination appears in several places in Smith's framework. One form stems from the possibility of a satisficing conception of how we should handle the value of agency. It is possible that someone seeking advice would be happy with advice from an agent who is good enough rather than from one who is ideal. We are free to attribute functional perfection to all kinds of things without for that reason thinking that we are somehow normatively required to care about having the best versions - if a perfectly sharp knife is an ideal knife, I do not need a perfectly sharp knife to cut myself a piece of bread, just one that does the job. Similarly, a merely good enough agent might have desires that are good enough to count as the sources of reasons. We need something more to think that perfect functioning is required to provide reasons.

Second, there does not seem to be any reason to pick out Smith's ideal advi- 
sors rather than several other advisors even if we aim for perfect advice. A less than fully coherent, yet still idealized, version of me might have desires for lasagna $(L)$, mac and cheese $(M)$, and spaghetti carbonara $(S)$, but desire lasagna over mac and cheese $(L>M)$, mac and cheese over spaghetti carbonara $(M>S)$, and spaghetti carbonara over lasagna $(S>L)$. These desires are intransitive, and therefore incoherent. But that version of me might also always desire spaghetti Bolognese over any of the other dishes, leaving the intransitive desires moot, because-assuming, in this case, that my reasons vary with the strength of my desires-I will always have more reason to cook spaghetti Bolognese rather than any of the other dishes. It is not obvious that we ought to prefer Smith's view to this one when it comes to accounting for the reasons we have.

There are potential replies here. Smith thinks that the desires of ideal agents grant us reasons because they are authoritative, unlike other desires. ${ }^{50}$ They are preferable to the desires of less than ideal agents for two reasons. First, he thinks, we tend to find out what we have reason to do by deliberating. Second, the extension of what we have reason to do is well captured by what we would be motivated to do if we deliberated well. ${ }^{51}$

It is unclear how these points have bearing on the underdetermination worry, however. We may well find out what we have reason to do by deliberating well enough, and the extension of what we have reason to do may well be fixed by what we are motivated to do if we reason well enough. So the satisficing worry stands. Similarly, intransitivities among desires we do not actively consider need not trouble our deliberation in practice, and hence the extension of what we have reason to do may well be compatible with cases such as the pasta case. It is very plausible that even an ideal version of me would not even consider making lasagna.

Another potential reply is that we might want to do more normative thinking prior to going constitutivist. Then we can, maybe, settle how we ought to treat the value of agency in terms of which we explain reasons, and then go on to defend some form of constitutivism based on the kind of agency we believe to be valuable for that reason.

Smith, "Constitutivism."

An anonymous reviewer has suggested two other lines of defense for Smith, but neither is very helpful. First, it does not help to say that fully functional or coherent agency is the best form of agency, and hence what we should care about. Again, it may be that we should satisfice, or maybe we could aim for perfect advice about some limited subset of questions rather than all, or something else insofar as we are trying to account for reasons. Nor does it help to suggest that Smith's ideal advisors have desires that are close to ours and hence are not alienated, because the desires of shmideal agents can be just as close-or possibly even closer, as they may share some of our flaws. 
I admit that this strategy seems open, but the reply essentially concedes the problem. We need to explain how to handle the goodness of agency to avoid the underdetermination worry. There is more work to do to explain what we are supposed to do with the value of agency before we can explain things in terms of it. This task need not be impossible, but it seems very hard. And partial constitutivism is an incomplete view until we know how to treat valuable agency, and therefore which norms it is supposed to explain.

\section{CONCLUSION}

What have we learned? In section 1, I presented the shmagency objection, and in section 2 I showed that the standard line of defense-self-defeatingnessseems to hold against criticism. But then I argued, in sections 3 and 4 , that the shmagency objection remains because there is still an external standpoint, occupied by sophisticated shmagents, that constitutivists cannot handle. After that, in section 5, I argued that partial constitutivists can defend themselves against the argument by denying P1 rather than P2. But in section 6, I argued that this response fails due to another shmagency objection stemming from underdetermination.

From this discussion, one might conclude that constitutivism (about normatively forceful practical reasons, at least) still fails in virtue of the shmagency objection. But that conclusion seems hasty. There may still be versions of constitutivism that can avoid the sophisticated shmagents, and that are not based on underdetermined values. But just how such versions might look is better discussed elsewhere. My main conclusion is, instead, that constitutivists will need to avoid the challenges presented above to still be able to explain normatively forceful practical reasons. ${ }^{52}$

University of Leeds
prol@leeds.ac.uk

52 I want to thank audiences at the universities of Leeds, York, and Sheffield, as well as at Humboldt-Universität zu Berlin, for comments on previous versions of this paper. Special thanks go to Pekka Väyrynen, Ulrike Heuer, Daniel Elstein, Thomas Schmidt, Janis Schaab, Luca Ferrero, Caroline Arruda, Gabriel Nyberg, and Alexios Bréhier-Stamatiadis for help at various points during the development of this paper, as well as to anonymous reviewers for this and other journals for insightful suggestions for improvements. My time at Humboldt was part of a collaboration with the University of Leeds, and I was funded by Erasmus + to go there. I thank the EU for setting up that scheme. 
Arruda, Caroline T. "Why Care about Being an Agent?" Australasian Journal of Philosophy 95, no. 3 (2017): 488-504.

Bagnoli, Carla, ed. Constructivism in Ethics. Cambridge: Cambridge University Press, 2013.

Bratman, Michael E. "The Rational Dynamics of Planning Agency." The Pufendorf Lectures, Lund University, June 7, 2016. http://www.pufendorf.se/ sectione195f.html.

Enoch, David. "Agency, Shmagency: Why Normativity Won't Come from What Is Constitutive of Action." Philosophical Review 115, no. 2 (April 2006): 16998 .

. "Shmagency Revisited." In New Waves in Metaethics, edited by Michael S. Brady, 208-33. New York: Palgrave MacMillan, 2011.

Ferrero, Luca. "Constitutivism and the Shmagency Challenge." In Oxford Studies in Metaethics, vol. 4, edited by Russ Shafer-Landau, 303-32. Oxford: Oxford University Press, 2009.

—. "Inescapability Revisited." Manuscrito 41, no. 4 (2018): 113-58.

Finlay, Stephen. "Defining Normativity." In Dimensions of Normativity: New Essays on Metaethics and Jurisprudence. Oxford: Oxford University Press, forthcoming.

Katsafanas, Paul. Agency and the Foundations of Ethics. Oxford: Oxford University Press, 2013.

Korsgaard, Christine M. Fellow Creatures: Our Obligations to the Other Animals. Oxford: Oxford University Press, 2018.

- Self-Constitution: Agency, Identity, and Integrity. Oxford: Oxford University Press, 2009.

. The Sources of Normativity. Cambridge: Cambridge University Press, 1996.

Lavin, Douglas. "Forms of Rational Agency." Royal Institute of Philosophy Supplements 80 (July 2017): 171-93.

O’Hagan, Emer. "Shmagents, Realism and Constitutivism about Rational Norms." Journal of Value Inquiry 48, no. 1 (March 2014): 17-31.

Paakkunainen, Hille. "Doing Away with the 'Shmagency' Objection to Constitutivism." Manuscrito 41, no. 4 (2018): 431-80.

Pettit, Philip, and Michael Smith. "Backgrounding Desire." Philosophical Review 99, no. 4 (October 1990): 565-92.

Rosati, Connie S. "Agents and Shmagents: An Essay on Agency and Normativ- 
ity." In Oxford Studies in Metaethics, vol. 11, edited by Russ Shafer-Landau, 182-213. Oxford: Oxford University Press, 2016.

Silverstein, Matthew. “The Shmagency Question.” Philosophical Studies 172, no. 5 (May 2015): 1127-42.

Smith, Michael. "Agents and Patients, or: What We Learn about Reasons for Action by Reflecting on Our Choices in Process-of-Thought Cases." Proceedings of the Aristotelian Society 112, no. 3 (October 2012): 309-31.

- "Constitutivism." In The Routledge Handbook of Metaethics, edited by Tristram McPherson and David Plunkett, 371-84. New York: Routledge, 2017.

. "The Magic of Constitutivism." American Philosophical Quarterly 52, no. 2 (April 2015): 187-200.

- The Moral Problem. Oxford: Blackwell Publishing, 1994.

Tiffany, Evan. "Why Be an Agent?" Australasian Journal of Philosophy 90, no. 2 (2011): 223-33.

Velleman, J. David. How We Get Along. Oxford: Oxford University Press, 2009. 